\title{
LATIDOS DE UN POETA ROBOT
}

\section{Delmiro ROCHA}

UNED

\author{
delmiroquai@gmail.com
}

\begin{abstract}
Con todo penso que o eu dun poeta non é unha instancia escindida senón ela/el mesm* a propia segregación, que o eu dunha poeta [...] coincide plenamente coa división, de aí que non avance seguindo un ritmo de contrarios senón os acordes dunha independencia. Pensar na posibilidade de trazar un retrato robot dunha/dun poeta contemporáneo (Pato, 2009: 89). ${ }^{1}$
\end{abstract}

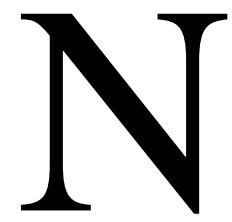

hablaré de la poesía.

¿Quién puede hacerlo?, ¿hoy?, ¿quién puede salir, hoy, del lenguaje poético o poemático, y elevarse como la mariposa o arrastrarse como el erizo, para contemplar desde el afuera de la poesía a la poesía y decir así, sin poiesis, la poesía? ¿Quién se arroga el derecho, la autoridad del derecho, la autoritas del discurso sobre -envoltura o envoltorio-, acerca de, encima de, relativo a la poesía y sin caer en ella, en su suelo, tomber par terre, no chan, o incluso más abajo, a dos metros bajo tierra, en la sepultura de sí misma, tombe, perdiendo ya el sujeto o el autos del discurso, de la frase, ésta o aquélla, para decir lo que ella dice o quiere o debe decir? Peor: ¿No es semejante intento, éste y aquél, la solicitación del intento, una forma de caer (de sepulcro) en él?

No hablaré, pues, de la poesía.

Pero quizá sea posible hablar de lo poético, de lo poemático, de la poiesis, de la creación del/la poeta. No evitaremos la traducción. Tampoco evitaremos el lenguaje que, al menos desde el gran banquete nupcial de la metafísica, nos obliga siempre a

\footnotetext{
${ }^{1}$ «Con todo pienso que el yo de un poeta no es una instancia escindida sino ella/el mismo* la propia segregación, que el yo de una poeta [...] coincide plenamente con la división, de ahí que no avance siguiendo un ritmo de contrarios sino los acordes de una independencia. Pensar en la posibilidad de trazar un retrato robot de una/un poeta contemporáneo» (Trad. D. R., todos los textos de Chus Pato han sido traducidos expresamente para este artículo por el autor del mismo y en adelante no se señalará).
} 
crear ser, a pasar (tránsito, traslación, transporte, paso, viaje, óbito) de un lugar a otro.

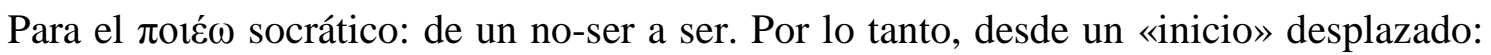
la traducción.

Después de la dilación, y antes de regresar a ella, dos confesiones:

1. Intención: trabajar con dos escrituras, Chus Pato y Jacques Derrida, nombres y metonimias. Poeta y filósofo y ante todo, cada uno a su manera, à sa façon, ao seu xeito, no solamente eso.

2. Propuesta: arriesgar un retrato del poeta contemporáneo como robot con memoria, esto es, con corazón sin ligazón esencial a una poiesis.

El primer paso es ya dilatorio -dilať̌o -ōnis (experimentar, sufrir)-, paso que difiere o retrasa, traducción como experiencia, no de esto o de aquello, sino como experiencia misma sin estaticidad, sin estatismo ni estado, por lo tanto sin mismidad o identidad estáticas; experiencia del tránsito, del paso que sufre la experiencia. Si hubiese una interpretación política de lo poético empezaría en este movimiento.

Este primer paso, anterior a la intención, supone una traducción: escribir a Pato y a Derrida en castellano o español. La multiplicidad primera de las lenguas no sería aquí reducible a una intermedia, como lugar intermedio de encuentro o entendimiento, como entre Galicia y Francia, como lugar público de reconocimiento, como publicación. Más bien, esta transferencia sin regla daría un lugar nuevo, un nuevo lugar al lugar, un lugar sin topos previo, una marca, una oportunidad para la a-poiesis que ha de ser firmada. Y ha de ser firmada por otro, por otros o, al menos, no simplemente por uno. No hay aquí, pues, reunión.

\title{
I. Del erizo a la mariposa: vuelos a ras de suelo
}

\begin{abstract}
Il faut choisir, ou plutôt, être attentif à la limite d'un choix que nous n'avons même plus à faire. Le poème, l'expérience poématique, celle dont il est dit «un poème, je ne le signe jamais», le poème sans poésie, seul un hérisson de catachrèse peut encore s'y livrer (Derrida, 1992: 322). ${ }^{2}$
\end{abstract}

Derrida, quien ha vuelto porosas y permeables las fronteras que pretendían separar la literatura de la filosofía, se confiesa amante de la literatura pero incapacitado para

\footnotetext{
${ }^{2}$ «Hay que elegir o, mejor, estar atentos al límite de una elección que ya ni siquiera hemos de hacer. Sólo a un erizo de catacresis puede entregarse todavía el poema, la experiencia poemática, aquella de la que se dice "un poema yo no lo firmo/yo no lo firma jamás" (un poème je ne le signe jamais), el poema sin poesía» (Derrida, 1989-90b: 180).
} 
ella. «Siempre tengo la impresión que el discurso es desigual a la historia que me gustaría contar, por lo tanto renuncio, renuncio todo el tiempo» (Derrida, 2002: s. p.). Esta humildad exagerada muestra una renuncia significativa. Una actitud que quizá define, sin por eso subsumir en concepto, cierta actitud poemática. ¿A qué renuncia tal renuncia? Si hay una renuncia, ésta tendría que ver con la soberanía del discurso. El yo no domina su discurso, su decir ya no es suyo, no le pertenece, no hay propiedad, pertenencia, ni posesión. Quizá, simplemente, reste una apendencia engañosa, esto es, un accesorio que se anuda con lazo íntimo a lo pretendidamente principal hasta confundirse con él, hasta suplantarlo o suplementarlo. Se renuncia, entonces, al logos pleno, uno, único, esto es, a la palabra pura, a la verdadera palabra que dice la palabra verdadera, la verdad pura de la palabra divina, la creación de la verdad por medio de la palabra, verbo, poiesis. ¿Qué dice, pues, la poesía?

No hablaré de la poesía. De esa que atribuye clásicamente su cadencia a la versificación, a la medida estricta de un ritmo musical, a la adecuada distribución de sus figuras. De esa que se nutre de las formas bellas y pretende ser una de ellas, un género literario exquisito.

El anti poeta Nicanor Parra ilustra con humor reflexivo la contaminación prosaverso en el antipoema titulado «Somos dos estudiantes de pedagogía»:

\author{
Al profesor no se le entiende nada \\ Sáquenos de la duda don Nicanor \\ ¿En qué se distingue la prosa del verso? \\ -¿Diferencia? ¡Ninguna! \\ Es cuestión de costumbre solamente \\ Los poetas escriben para abajo \\ Los prosistas escriben para el lado \\ En un lugar de la Mancha \\ (octosílabo) \\ de cuyo nombre no quiero acordarme \\ (endecasílabo)
}

Si en la búsqueda de la cosa, de la esencia de la cosa, de su paso al ser; si en la experiencia de la búsqueda de esa cosa y por lo tanto ya en la cosa, ya en la cosa como experiencia que es un paso o tránsito, se renuncia a la esencia propia de la cosa, ¿no es esa renuncia parte de la cosa?, ¿no sería la renuncia algo «constitutivo» -por usar una palabra que sin duda emplearía antes de la renuncia a la esencia de la cosa y no después- de la cosa? Si esto fuese así significaría que sólo podríamos hablar de la poesía renunciando a encerrarla en concepto. No hablaré, pues, de la poesía. Quizá esto es lo que hace don Nicanor. Sin embargo, firma el giro y lo bautiza antipoema. Este gesto sería más que suficiente para denunciar que ha sido atrapado por aquello mismo que pretendía atrapar a su manera, es decir, romper o hacer temblar su significación, su 
conceptualización de enciclopedia. Aquí es donde la pluma de Derrida corta con doble filo.

«Un poème, je ne le signe jamais». «Un poema yo no lo firmo jamás». Ciertamente, Derrida nunca ha firmado un poema, así como tampoco ha incrustado su sello en una novela ni en una obra de teatro. Su renuncia es expresa, como se puede leer más arriba. Pero el doble filo, la otra cara de la cortante hoja, la amenaza, siempre efectiva, de incisión sangrante, corte, tajo, hendidura o herida que porta la traducción y que nunca deja intacto el corazón vivo de la lengua, que siempre daña en su transporte y deja huellas rojas allí donde pretende establecerse, ataca aquí al corazón de la frase, al sujeto. Es el «yo» quien «no firma el poema jamás» («Un poème, je ne le signe jamais»). El poema estaría carente de sujeción metafísica y quizá por eso hay que decir siempre quizá. «Sans sujet: il y a peut-être du poème et qui se laisse, mais je n'en écris jamais. Un poème je ne le signe jamais» (Derrida, 1992: 307) ${ }^{3}$. No lo firma, no lo sella, no se lo apropia a través del nombre escrito que representa la unidad del yo propietario del poema y del nombre, del yo que lo escribe. El poema no es la hacienda intransferible de un yo que lo ha creado según las viejas leyes de la poiesis. No hay paso socrático sino traducción imposible. «Il n'y a jamais que du poème, avant toute poièse» (Derrida, 1992: 307) ${ }^{4}$. La cesura en el corazón es la marca del poema, el poema como marca de la singularidad absoluta de la muerte.

Tu appelleras désormais poème une certaine passion de la marque singulière, la signature qui répète sa dispersion, chaque fois au-delà du logos, anhumaine, domestique à peine, ni réappropriable dans la famille du sujet : un animal converti, roulé en boule, tourné vers l'autre et vers soi, une chose en somme, et modeste, discrète, près de la terre, l'humilité que tu surnommes, te portant ainsi dans le nom au-delà du nom, un hérisson catachrétique, toutes flèches dehors, quand cet aveugle sans âge entend mais ne voit pas venir la mort (Derrida, 1992: 307). ${ }^{5}$

Desde ahora llamaré poema a una determinada pasión por la marca singular que se encuentra por doquier en Derrida, la firma que repite su dispersión y que no deja de asediarme, cada vez más allá del logos, como Derrida ha hecho y enseñado. Si el humano occidental es logocéntrico la marca del poema derridiano es no humana, apenas doméstica, ni por supuesto reapropiable en la familia del sujeto. L'animal que je suis convertido en o hecho un ovillo, vuelto hacia el otro siempre antes que hacia sí mismo,

\footnotetext{
3 «Sin sujeto: quizás hay poema, y quizás se deja, pero yo jamás escribo ninguno. Un poema yo no lo firmo/yo no lo firma jamás» (Derrida, 1989-90a: 169).

4 «No hay nunca más que poema antes de toda poesía» (Derrida, 1989-90a: 169).

5 «Desde ahora llamarás poema a una determinada pasión por la marca singular, la firma que repite su dispersión, cada vez más allá del logos, no humana, apenas doméstica, ni tampoco reapropiable en la familia del sujeto: un animal convertido en o hecho un ovillo, vuelto hacia el otro y hacia sí mismo, una cosa en suma, y modesta, discreta, a ras de tierra, la humildad a la que tú das el sobrenombre -yendo así en el nombre más allá del nombre- de erizo catacrético, con todas las flechas hacia fuera, cuando este ciego sin edad oye pero no ve venir la muerte» (Derrida, 1989-90a: 169).
} 
muchas cosas en una, y modesta, discreta, a ras de tierra, la humildad a la que yo daba el sobrenombre de exagerada -yendo así en el nombre más allá del nombre, como la deconstrucción-, ¿qué, a quién, quoi ou qui, esconde la catacresis del erizo?

Los alfileres del erizo aguijonean el corazón del poema. Sus afiladas puntas muestran un doble riesgo. Este es el riesgo de la traducción. Defensa necesaria pero imposible.

Amenaza de corte si intentas tocarme/muero por atropello si me tocas. Final.

La traducción (se) resiste siempre. No se deja mancillar y su vilipendio es necesario. Y lo que más resiste a la traducción es el poema. Él es la prueba ineludible de que es necesario crear un texto nuevo para traducir el poema tal como es. El poema es el abismo total de la traducción. Esta dificultad aporética se muestra en los textos de Derrida a cada paso. Traducir a Derrida es traducir el poema.

Así como el poema del filósofo Derrida encuentra dos erizos más en Ick bünn all hier. «Ya estoy aquí», a saber, Schlegel y Heidegger, la filosofía de la poeta Chus Pato cruza esa misma autopista, peligrosa para todo sujeto, en su libro Hordas de escritura. Justo antes de empezar, después de un pequeño prefacio de una página que ella misma escribe [página 9] y justo antes de Termidor (episodio primeiro) [página 13] que anuncia el principio del primer capítulo o episodio, hay una cita a modo de exergo precisamente de Schlegel: «A poesía é un discurso republicano: un discurso que é el mesmo a súa propia lei e o seu propio fin, e no que todas as partes son cidadáns libres que teñen o dereito de pronunciarse para poñerse de acordo» $\left(\right.$ Pato, 2008: 11) ${ }^{6}$.

Antes del contenido político-semántico, sin duda cuestionable, sobre todo aquello que refiere a la ley «interna», ley «propia» que coincide con su «propio» fin, al concepto de ciudadanos libres y a la duplicidad de fines que establece un fin interior (el sí mismo) y otro exterior (el acuerdo), antes, pues, de todo ello encontramos una definición de la poesía: «La poesía es un discurso republicano». Es decir, la poesía es discurso sin soberano, un discurso no soberano. Y aunque es difícil pensar en un discurso que mantiene el sí mismo pero le expropia su soberanía, esto es, un sí mismo que no es dueño de sí, en todo caso pervive el discurso. La poesía es un discurso (¿alegato, alocución, charla, diatriba, disertación, homilía, plática, prédica, conferencia, mitin, amonestación, sermón?) que pone en jaque la rígida distinción entre verso y prosa. La cuestión aquí no es formal, como ironizaba don Nicanor, sino filosófica. ¿La prosa dice o pretende decir lo que es y el verso expresa o pretende expresar lo que siente?, ¿se puede todavía hoy hacer esta distinción?

\footnotetext{
${ }^{6}$ «La poesía es un discurso republicano: un discurso que es él mismo su propia ley y su propio fin, y en el que todas las partes son ciudadanos libres que tienen el derecho de pronunciarse para ponerse de acuerdo» (Pato, 2008: 11).
} 
Hordas de escritura es un ejemplo vivo de esta contaminación. Mantiene discurso detrás de una versificación sin mesura y camina sobre la tensión abisal del decir expresivo-enunciativo. No hay texto propiamente en verso ni propiamente en prosa. El problema es precisamente el «propiamente», lo «propio» del texto se rebela contra todo intento de agarrar(la) propiamente. El discurso no es simplemente perorata prosística ni contenido enunciativo ni raciocinio. Además -quizá sobre todo- es transcurso, decurso, discurrir, pasar, movimiento ineludible de la traducción cubierto de púas afiladas. «[...] este estado perpetuo de pasaxe: todo tipo de signos, afectos, mensaxes, do que sexa / como o rostro monstruoso da liberdade, este slálom de abismos» (Pato, 2008: 17) ${ }^{7}$. Parece que en Pato el discurso que anuncia Schlegel se entiende mejor en este sentido de paso (pas), de negación de una estaticidad del sentido, de rechazo a la parálisis del concepto. Hay poema derridiano.

Conforme pasaban os anos -dixo- a necesidade de comunicación oral víase substituída por unha proliferación automática de síntomas corporais: lagoas, vertixe, desorientación, desinterese no que ela mesma comentaba, ou mesmo por una fala como a de quen, sentíndose violentada, vese no pulo de falar e nese esforzo emite palabras achegadas a unha linguaxe da loucura e tamén por un protocolo escritural inconcluso sempre que de acadar un termo non é este por gozo senón por esgotamento ou cansazo e que nesta retirada da voz sentía un acercamento progresivo á vaporización da presenza ou rumbo definitivo cara a un acabamento ou noción da morte (Pato, 2008: 18-19). ${ }^{8}$

Este paso que perfila la dificultad del pensamiento, su inquietud, no excluye el contenido filosófico-político-enunciativo, más bien lo tiñe de una responsabilidad sin precedentes que se abre sobre lo otro, que viene del otro, que no se cierra sobre sí. «O seu non era un temperamento xenuinamente revolucionario, máis ben rebelde e leal, absorto nunha cicatriz que dificilmente curaba» (Pato, 2008: 23) ${ }^{9}$. Parece señalar aquí el erizo derridiano cuya cicatriz incurable no deja de escribir su poema filosófico. El poema es una circuncisión, una marca ensangrentada que habita la escritura y que la asedia dividiendo la ficción del yo. La problemática de la identidad (yo, moi, je, eu) se radicaliza en el poema. Nada asegura la sujeción del verso. Está solo, en el aire. Se sostiene inquieto por el viento que lo lleva. Aletear imparable de mariposa. «[...] onde se está a soas co tempo e o eu e un innumerábel que multiplica e se descentra» (Pato,

\footnotetext{
${ }^{7}$ «Ni siquiera su continuado tránsito, este estado perpetuo de paso: todo tipo de signos, afectos, mensajes, de lo que sea / como el rostro monstruoso de la libertad, este slalom de abismos» (Pato, 2008: 17).

${ }^{8}$ «Así como pasaban los años -dijo- la necesidad de comunicación oral se veía sustituida por una proliferación automática de síntomas corporales: lagunas, vértigo, desorientación, desinterés en lo que ella misma contaba, o incluso por un habla como la de quien, sintiéndose violentada, se ve en el impulso de hablar y en ese esfuerzo emite palabras próximas a un lenguaje de la locura y también por un protocolo escritural inconcluso siempre que de alcanzar un término no sea este por goce sino por agotamiento o cansancio y que en esta retirada de la voz sentía un acercamiento progresivo a la vaporización de la presencia o rumbo definitivo hacia un acabamiento o noción de la muerte» (Pato, 2008: 18-19).

${ }_{9}$ «El suyo no era un temperamento genuinamente revolucionario, más bien rebelde y leal, absorto en una cicatriz que difícilmente curaba» (Pato, 2008: 23).
} 
2008: 41) ${ }^{10}$. Así habla la narradora de Termidor. Pero, ¿quién escribe?: «je n'en écris jamais». Todo agarre es protético, externo, y no vuelve a sí. No se explica su volar más que como ficción que alguien necesita firmar. Que otro firma con tu nombre para agarrar(te) al poema. Necesidad cognoscitiva de llamar poeta y poesía. Es menester su definición, su búsqueda entendida como encuentro, para la tranquilidad del pensamiento. Así la mariposa vuela alocada el poco tiempo que tiene. Y la detienen. «Se isto [...] que agora mesmo ve é prótese do soño, que sorte de tecnoloxía é o poema?» (Pato, 2008: 41) ${ }^{11}$. El robot aparece sobre nosotros como un sujeto insoslayable. ¿Tendrá el robot aprensión identitaria, miedo a la muerte, temor a la voz? En el tercer capítulo o división de Hordas de escritura titulado «os paxaros queriámolos ser e non nos gustan os prismáticos» ${ }^{12}$ (Pato, 2008: 47) se recogen estos miedos y se liberan en el poema. Empieza así: «A voz era pánico / e desexaba, insistía, ter hábito(s) no poema» (Pato, 2008: 49) ${ }^{13}$. Es como si todo poema pasase alguna vez por Alemania. Quizá Auschwitz sea el final de la poesía, el comienzo del poema, «le poème sans poésie». La prueba definitiva del constante arrastrarse. Poema político que ya no puede depender de la forma bella. Aguijón de muerte. Y último vuelo.

Máis que entrar no mundo do poema

botar por fóra a escritura, como unha lava lene e transparente, muselina tanto ceo tanta primavera

ves, isto é un acto político: torcerlles a vontade aos que obedecen pero falta o contexto.

E que dicir dos soportes!, cando xa o papel non atura e só é concibíbel unha parede e a proxección de letras dixitais (seguramente nun museo ou nos paneis da autoestrada) ou esas mesmas frases envolvendo como cintas luminosas os corpos dos viandantes que dialogan sobre o voar das aves ou os bucles dos miñatos que se mimetizan coas árbores cando estenden as ás coma un niño

a teoría é esa violencia ética do intanxíbel e está o problema do eu, cantos? e das situacións prefiro o meu pánico a entrar nas librerías (Pato, 2008: 49-50). ${ }^{14}$

\footnotetext{
10 «donde se está a solas con el tiempo y el yo es un innumerable que multiplica y se descentra» (Pato, 2008: 41).

${ }^{11}$ «Si esto que ahora mismo ve es prótesis del sueño, ¿qué clase de tecnología es el poema?» (Pato, 2008: 41).

12 «Queríamos ser pájaros y no nos gustan los prismáticos» (Pato, 2008: 47).

13 «La voz era pánico / y deseaba, insistía, tener hábito(s) en el poema» (Pato, 2008: 49).

14 «Más que entrar el mundo dentro del poema / echar por fuera la escritura, como una lava lene y muselina / tanto cielo / tanta primavera / ves, esto es un acto político: torcerles la voluntad a los que obedecen/pero falta el contexto. / ¡Y qué decir de los soportes!, cuando ya el papel no soporta y sólo es concebible una pared y la proyección de letras digitales (seguramente en un museo o en los paneles de la autovía) o esas mismas frases envolviendo como cintas luminosas los cuerpos de los viandantes que dialogan sobre el volar de las aves o los bucles de los milanos que se mimetizan con los árboles cuando extienden las alas como un nido / la teoría es esa violencia ética de lo intangible / y está el problema del yo, ¿cuántos? y de las situaciones / prefiero mi pánico a entrar en las librerías» (Pato, 2008: 49-50).
} 
La más fría de las primaveras alemanas rompió para siempre la poesía. ¿Quién se atreve a hablar de ella?, ¿a decirla? Todos y ninguno, sin duda. Semejante torcimiento es obligatorio antes de ser político. Y ya nadie más podrá decir la poesía. ¿Con qué pluma escribirá el robot y sobre qué papel?, ¿cuántos yo albergará?

Y el otro erizo derridiano aparece terrible poco a poco. Quizá el último yo. Aparece lentamente cuando aparece la muerte y lo hace sin determinar el sujeto, sin nombrarlo, como anticipando ya su huída, como anunciando su última voz:

creo -proseguiu- que o meu único interlocutor é a morte; dalgunha maneira escribo para que a morte, sexan cales sexan as circunstancias, non poida ser envilecida

[...] Definición: poeta é o non poeta

Proposición I: verdadeiramente poeta é aquela/aquel cuxa musa foi integramente destruída

Escolio: se quen escribe poesía é aquel/aquela cuxa musa foi destruída, isto significa que a identidade entre poeta e non poeta nunca é perfecta, que non é posíbel destruír integramente a musa, que sempre resta algo. Ser poeta é ser ese resto (Pato, 2008: $57-58) .{ }^{15}$

¿El robot tendrá musa?, ¿y yo escindido?, ¿entenderá la no identidad, siempre presa de su contrario?, ¿será un robot para la muerte?, «como sería entón o noso seraí?» (Pato, 2008: 66) ${ }^{16}$. El erizo heideggeriano entra en la escena de esta escritura hordática sin dar su nombre, sin presentarse. El verdadero cambio robótico quizá habría que buscarlo ahí, ahí, esto es, más allá del ser-ahí, en Heidegger pero justo después de él, en el principio de su punto y final. Una vez más Heidegger parece ser un yo, el único yo, tecnificación todavía de pensamiento, pura, aquel que situado en medio, en medio de un siglo y del desastre, atrapado y presa de sí se vuelve hacia la poesía como escapatoria a un atolladero. Quizá, quizá. Tal vez fuese ese gesto el final de la poesía, esto es, el principio del poema filosófico. Él está en medio y se aguanta, se sujeta con fuerza y resiste todas las embestidas a pesar de saberse ya perdido. Quizá sea el último yo de la historia, el último yo de la filosofía. Pero no habría Derrida sin Heidegger y tal vez desde una firme y errática travesía haya posibilitado el primer poema sapiente, esto es, aquel que sabe renunciar al saber para anunciarlo. La poesía de Heidegger fue el trágico vuelo de una preciosa mariposa, vuelo enérgico y cortísimo. Como un gusano que buscando su ley propia, su ser mismo, su identidad, se ve obligado a mutar, a transformarse, a ser varios yo y a perecer, pues, rápidamente. Aunque siempre quedara la línea en bucle de su fundamental vuelo. «Podería ser así: dunha beira unha

\footnotetext{
${ }^{15}$ «Creo -prosiguió- que mi único interlocutor es la muerte; de alguna manera escribo para que la muerte, sean cuales sean sus circunstancias, no pueda ser envilecida [...] Definición: poeta es el no poeta / Proposición I: verdaderamente poeta es aquella/aquel cuya musa fue íntegramente destruida / Escolio: si quien escribe poesía es aquel/aquella cuya musa fue destruida, esto significa que la identidad entre poeta y no poeta nunca es perfecta, que no es posible destruir íntegramente la musa, que siempre resta algo. Ser poeta es ser ese resto» (Pato, 2008: 57-58).

16 «cómo sería entonces nuestro ser-ahí?» (Pato, 2008: 66).
} 
imposibilidade de escritura, doutra unha potencia de escritura (son simétricas como as ás dunha bolboreta), no medio Eu: Eu é unha greta. O poema inventa o que non concorda, so é leal á súa propia independencia e fermosura»(Pato, 2008: 61) ${ }^{17}$. El gusano estaría atrapado entre una imposibilidad de escritura y una potencia de escritura. Atrapado sin remedio, pues ellas son sus alas que le permiten volar, es en lo que se ha transformado para ser sí mismo, para ser ahí en su mundo frágil que a pesar de todo debe continuar. Y el gusano, el yo, es una grieta. Un orificio. Un himen que debe romperse para ser himen, que no es dentro ni fuera, que no es nunca yo.

Isto -concluiu- é o estatuto ou territorio dun poeta

poeta é unha humana calquera.

Malia que a algúns os cega a claridade do alustro, tamén a outras as cega a cicatriz da noite

-teño que consideralo, o que ti denominas un ego deliberadamente esquizo... Mira, eu partía de núcleos distribuídos ou bifurcados, nos que un corte mantén ou divide un rostro siamés, bifronte

entón concibo o eu non precisamente como unha dislocación senón como ese argumento que sostén as partes (o eu sería a quinina do insecto, as cambiantes e nunca apreixábeis augas do río, o fiel da balanza). Dunha banda o así chamado "estado da natureza"; doutra a sintaxe, pero fluíndo ambos e dous, o un na outra

abismo que, como non ignoras, remite á fenda do sexo nas femias, abríndose cara aos labios de carne

tan diferente ao falo que se ergue cara a un infinito, amparado pola dilatación dos capilares sanguíneos (Pato, 2008: 61). ${ }^{18}$

El poema es un animal. Erizo y mariposa. Animal destripado en la gran autopista occidental. Órganos femeninos aplastados en la carretera. La voz de los muertos. La voz que un día intentó cerrarse en ser para la muerte e intentó poner manos a la obra de la verdad y fue destripada en la ruta y nadie limpió su sangre ni se llevó su cadáver ni hizo su duelo, esa voz vuelve sin palabra, muda, como el fantasma del erizo hembra atropellado. «Esa voz pode ser transportada no poema / esa voz é o poema / Certo, a voz do animal non pode ser escrita / pero esa non-palabra regresa / volve / e se repite / esa voz era Eu» (Pato, 2008: 64) ${ }^{19}$. El poema-hembra, siempre desterrado del reino del

17 «Podría ser así: de un lado una imposibilidad de escritura, de otro una potencia de escritura (son simétricas como las alas de una mariposa), en medio Yo: Yo es una grieta. El poema inventa lo que no concuerda, solo es leal a su propia independencia y hermosura» (Pato, 2008: 61).

18 «Esto -concluyó- es el estatuto o territorio de un poeta / poeta es una humana cualquiera. / A pesar de que a algunos los ciega la claridad del relámpago, también a otras las ciega la cicatriz de la noche / -tengo que reconsiderarlo, lo que tu llamas un ego deliberadamente esquizo... Mira, yo partía de núcleos distribuidos o bifurcados, en los que un corte mantiene y divide un rostro siamés, bifronte / entonces concibo el yo no precisamente como una dislocación sino como ese argumento que sostiene las partes (el yo sería la quinina del insecto, las cambiantes y nunca aprehensibles aguas del río, el fiel de una balanza). De un lado el así llamado "estado de naturaleza"; de otro lado la sintaxis, pero fluyendo ambos y dos, el uno en la otra / abismo que, como no ignoras, remita a la brecha del sexo de las hembras, abriéndose hacia los labios de la carne / tan diferente al falo que se levanta hacia el infinito, amparado por la dilatación de los capilares sanguíneos» (Pato, 2008: 61).

19 «Esa voz puede ser trasportada en el poema / esa voz es el poema / Cierto, la voz del animal no puede ser escrita / pero esa no-palabra regresa / vuelve / y se repite / esa voz era Yo» (Pato, 2008: 64). 
saber, abre ahora su grieta creadora lejana a la poiesis. Crisálida del saber que transforma su cuerpo animal en un paso que va más allá del saber, el no saber del saber que habla tan bien el francés, passage, transcurso, viaje alado a ras de suelo, paso, traducción sin regla, pas-sage.

Hay una animalidad liberadora en el poema que no se decanta hacia un lado de la balanza, que no trabaja en la lógica dual de la metafísica [«exclusión dobre, a do animal e a exclusión do logos» (Pato, 2008: 73) ${ }^{20}$ ] sino que es su fiel.

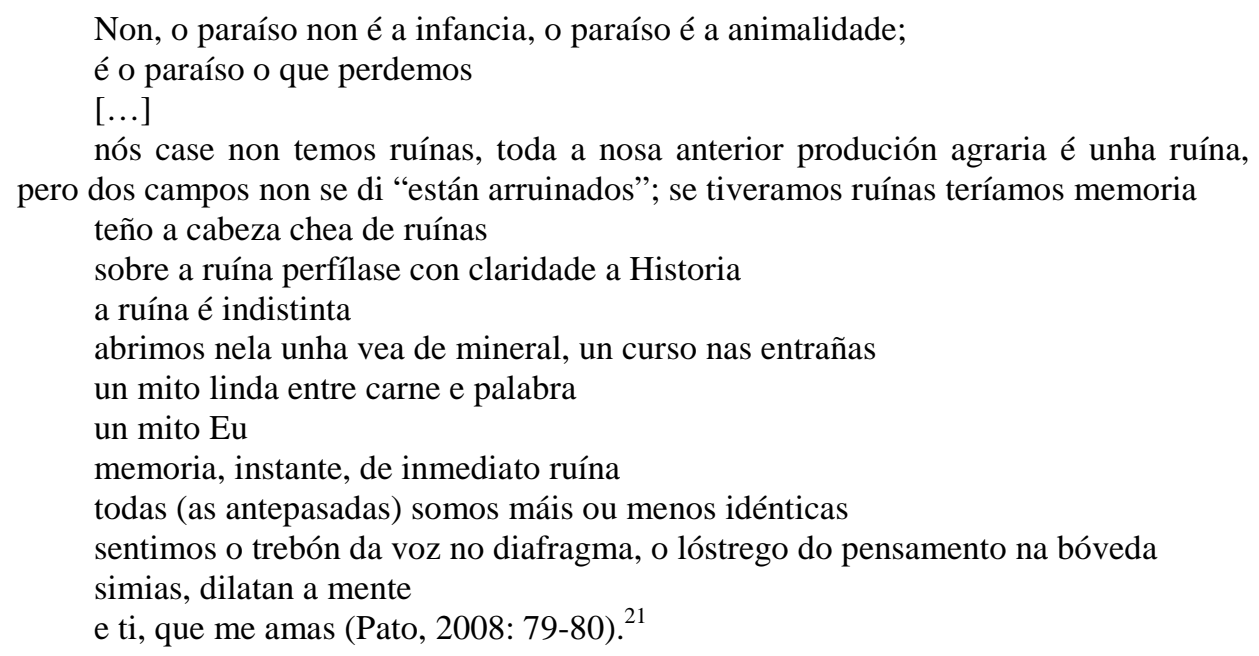

Se acabó el poema universal, la gran puesta en obra de la verdad. Hablaré solamente de mi ruina, pues, si hablase de la gran ruina, la ruina pura, sería una ruina. Lo que se machaca en la calzada es precisamente eso, la memoria, el corazón del animal. Y el latido que se pierde, ese del que se hace duelo aquí, es el latido del otro. Ese latido llega a mí -otra palabra para la identidad que se divide en la llegada- pero del otro, primero como otro, aunque sea mi latido el que llega como otro. El saber que se deconstruye en el poema no podrá ser simplemente enunciativo, ni simplemente lógico ni axiológico ni tecnológico. No podrá constituir un método o una doctrina, menos aún una ciencia o una filosofía, si por ello entendemos saber completo y sin fisuras, absoluto, que informa del mundo, y de las cosas del mundo, tal y como es. ¿Cuál sería el saber que aseguraría hoy esto? El seguro, la garantía, la fianza, etc., son todos sinónimos fiduciarios que constituyen la partida, el inicio del saber, su base. El saber,

\footnotetext{
20 «Doble exclusión, la del animal y la exclusión del logos» (Pato, 2008: 73).

${ }^{21}$ «No, el paraíso no es la infancia, el paraíso es la animalidad; / es el paraíso lo que perdemos [...] nosotros casi no tenemos ruinas, toda nuestra anterior producción agraria es una ruina, pero de los campos no se dice "están arruinados"; si tuviéramos ruinas tendríamos memoria / tengo la cabeza llena de ruinas / sobre la ruina se perfila con claridad la Historia / la ruina es indistinta / abrimos en ella una vena de mineral, un curso en las montañas / un mito linda entre carne y palabra / un mito Yo / memoria, instante, de inmediato ruina / todas (las antepasadas) somos más o menos idénticas / sentimos la tormenta de la voz en el diafragma, el relámpago del pensamiento en la bóveda / simias, dilatan la mente / y tú, que me amas» (Pato, 2008: 79-80).
} 
entonces, desde su ruina, es poemático. Pero no se renuncia a aprehender ni a recordar la aprehensión. Es una anamnesia de la rememoración. Volver a pasar por el corazón, coeur, cor, es el recuerdo y la memoria y la ruina del recuerdo. Y habrá que aprender, con Derrida, de memoria, par coeur, pues el latido que trae el recuerdo ruinoso y la ruina del saber vendrá como un dictado del otro. Lo que llegue o no llegue, el arribante, será en todo caso el poema del saber y vendrá como anamnesis de ese porvenir.

N'est-ce pas déjà cela, le poème, lorsqu'un gage est donné, la venue d'un événement, à l'instant où la traversée de la route nommée traduction reste aussi improbable qu'un accident, intensément rêvée pourtant, requise là où ce qu'elle promet toujours laisse à désirer? Une reconnaissance va vers cela même et prévient ici la connaissance: ta bénédiction avant le savoir (Derrida, 1992: 304-305). ${ }^{22}$

«¿No es déjà esto, el poema?» ¿Y si quisiésemos hacer esta traducción, enfrentarnos a sus puntas afiladas y herirnos con ellas? Derrida sería entonces el poema. Aquel poema que fue capaz de renunciar al saber metafísico, inmiscuyéndose y permaneciendo en él, para saber. Un poema que más allá del logos, y antes, pues, suspensión poemática del saber, supo alertar de que él no era el fiel. Qui?, quoi? Precisamente eso es lo que enseña, es lo que sabe, el poema derridiano. Si el fiel es el poema, eso querría decir que no hay fiel. Quizá tampoco balanza. Fidelidad infiel al poema. La memoria, el corazón, ya no sería aquel disco duro que retiene el saber sino aquello que retiene lo que al saber se le escapa. Apprendre par coeur. Lo otro del saber. El saber del corazón del otro. La conminación del otro es una bêtise. Hay animal(es) y no es poca cosa, aunque suene una tontería. El poema es ese animal expuesto al atropello que sale en su aleteo siempre hacia un afuera que ya no puede provenir simplemente de un adentro, del corazón como el afuera del otro, el afuera del afuera. La traducción es una crisálida dispuesta a copular. Y si el poema chusderridiano tuviese un yo, eu, moi, je, sería ese corazón de memorias rebelde a la simetría del latir. El insurrecto aprender de su desaparición. El otro que firma en su corazón.

Un poème je ne le signe jamais. L'autre signe. Le je n'est qu'à la venue de ce désir: apprendre par coeur. Tendu pour se résumer à son propre support, donc sans support extérieur, sans substance, sans sujet, absolu de l'écriture en soi, le «par coeur» se laisse élire au-delà du corps, du sexe, de la bouche et des yeux, il efface les bords, il échappe aux mains, tu l'entends à peine, mais il nous apprend le coeur. Filiation, gage d'élection confié en héritage, il peut se prendre à n'importe quel mot, à la chose, vivante ou non, au nom de hérisson par exemple, entre vie et mort, à la tombée de la nuit ou au petit jour, apocalypse distraite, propre et commune, publique et secrète (Derrida, 1992: 307-308) ${ }^{23}$.

\footnotetext{
22 «No es esto ya el poema, cuando se hace una promesa, la venida de un acontecimiento, en el instante en que la travesía del camino que se llama traducción parece tan improbable como un accidente y, no obstante, se sueña intensamente con ella, se la requiere allí donde lo que ella promete siempre deja algo que desear? Un reconocimiento va en esta dirección y previene aquí el conocimiento: tu bendición antes del saber» (Derrida, 1989-90a: 166).

${ }_{23}$ «Un poema yo no lo firmo/yo no lo firma jamás. El otro firma. El yo no es, no aparece más que cuando irrumpe ese deseo: aprender de memoria. Tenso a fin de resumirse en su propio soporte $\mathrm{y}$, por
} 


\section{El poeta robot}

Ahora es el momento / eres un robot sin programación logocéntrica / a-poietico / exapropiado / la tecnología que te constituye no es pura / no existes / eres el resto de lo que una vez se llamó humano / excremento / ruina / tus procedimientos no se cierran en sistema / error 404 / búsqueda y pérdida / a-destinación / tu disco duro infinito, políglota, perfectamente informado, minúsculo, necesita alimentación / eres ignífugo / eres ceniza / tienes grabado lo que dijo el poeta / lo imposible es lo único que puede ocurrir / no podrás evitar mantener tu latido metálico / no sabes que has renunciado al saber / eso no puede ser un saber / Apprendre par coeur / A saber, el corazón del otro.

\section{Bibliografía}

DERRIDA, J. (1989-1990a): “QQué es poesía?” Trad. C. de Peretti, Er, Revista de Filosofía, 9-10, pp. 165-170.

(1989-1990b): "Ick bünn all hier. «Ya estoy aquí». Conversación con Jacques Derrida. Entrevista de Maurizio Ferraris". Trad. C. de Peretti y P. Peñalver, Er, Revista de Filosofía, 9-10, pp. 171-190.

(1992): Points de suspension. Entretiens. Paris, Galilée.

(2002): Derrida. A Film by Kirby Dick and Amy Ziering Kofman. Jane Doe Films Inc. (DVD Video: Zeitgeist Films Ltd., 2003).

PATO, C. (2008): Hordas de escritura. Vigo, Xerais. (2009): Secesión. Vigo, Editorial Galaxia.

consiguiente, carente de soporte externo, de sustancia, de sujeto, absoluto de la escritura en sí, el "par coeur" se deja escoger más allá del cuerpo, del sexo, de la boca y de los ojos, borra los bordes, se escapa de las manos, lo oyes apenas, pero nos enseña el corazón. Filiación, promesa de elección confiada en herencia, puede captarse en cualquier palabra, en la cosa, viva o no, en el nombre de erizo por ejemplo, entre la vida y la muerte, a la caída de la noche o al despuntar el alba, apocalipsis distraída, propia y común, pública y secreta» (Derrida, 1989-90a: 170). 